\title{
Literature Review and Analysis of Current Research Status of Rural Financial Efficiency
}

\author{
Yue $\mathrm{Ma}^{1, \mathrm{a}}$, Fu-Xiang Liu ${ }^{1, \mathrm{~b}}$ \\ ${ }^{1}$ Harbin University of Commerce, School of Economics, Harbin, Heilongjiang Province, China
}

\begin{abstract}
Rural economic issues have attracted more and more attention from china, but there are still many problems of rural finance in China. Therefore, it is necessary to sort out the relevant literature on rural financial efficiency, and analyze the rural financial efficiency's connotation itself, the relationship with rural economic development, the factors affecting its efficiency, rural financial institutions and research methods from both macro and micro aspects. They are finally generalized and summarized to guide the direction of relevant policies.
\end{abstract}

\section{INTRODUCTION}

At the beginning of the 21st century, in the context of Chinese basic goal of building a new countryside, the three agricultural issues have been emphasized for many years in the No. 1 document of the central government, which highlights the importance and urgency of promoting the construction of urban-rural integration and revitalizing the rural economy in an all-round way. When emphasizing the rural economy, rural finance cannot be avoided. The analysis of rural financial efficiency reveals the essential problems of rural finance. However, the current rural financial system and operation conditions fail to make full use of rural savings funds, with the low efficiency of resource allocation, at the same time, agricultural financial surplus flows continuously to cities and industries at very low cost, forming a systematic negative investment phenomenon, which is not conducive to the development of the rural economy. As a result, there is a growing gap between rural and urban economic development, resulting in a dual economic structure. Therefore, the current rural financial system cannot shoulder the important mission of supporting rural economic development and the transformation and upgrading of agricultural industrial structure. The largescale withdrawal of state-owned commercial banks from rural areas is even worse. Banks such as postal savings have also played a role in absorbing financial surplus, with the low savings mobilization capacity of rural credit cooperatives, the defect of the property rights system, and the increasing commercialization. All of these are not conducive to the efficient performance of rural finance. As a result, in the context of the above conditions, it is necessary to sort out the existing research results of china's rural financial efficiency, which also provides a relevant theoretical basis and direction for the implementation of the following Chinese policy.

\section{RESEARC ON CHINA'S RURAL FINANCIAL EFFICIENCY}

The dual economic structure is a typical economic phenomenon in China. Western financial development was relatively early, and it has matured so far, so there is no dual economic structure. China's research on rural financial efficiency can be roughly divided into two levels: macro level and micro level. The macro level has the following aspects: 1) The perspective of the connotation of rural financial efficiency itself; 2) The related research on rural financial efficiency under the theme of rural financial development and economic growth; 3) The deeper reason of differences in rural financial efficiency in the eastern, central and western regions; 4) The main several factors affecting the level of rural financial efficiency; 5) the main focus of micro level is on the mechanism of rural credit cooperative institutions and the level of China's rural financial efficiency.

\subsection{The Macro Aspect}

1) Regarding the connotation of rural financial efficiency (quantifying the relationship between financial element input and economic output, under the premise of a certain level of technology), Qi-Zhi Deng analyzed rural financial efficiency of China from the six core financial functions. And on this basis, he proposed some corresponding solutions [1]. Bing-You Cheng studied the current financial inefficiency in China and also proposed some corresponding ways to improve it [2]. The rural financial efficiency from Hong-Dan Zhao refers to the ability of China's rural financial intermediaries and other institutions to convert rural residents' savings into

aE-mail address: 13353453507@163.com, bE-mail address: liufuxiang2009@163.com 
agricultural loans, expressed in terms of rural savings ratio, which has a positive effect on rural economic growth [3]. 2) Under the theme of rural financial development and economic growth, there are many research results on financial efficiency. Hong-Mei Wen conducted an empirical analysis on 2001 county-level data in China, using a four-stage DEA model, and the results showed that the rural financial input in China has a large amount of redundancy, with a poor financial efficiency throughout the country [4]. The research results from Ji-Gang Li show that the low level of pure technical efficiency of China's rural finance in the central and western regions has led to poor resource allocation efficiency. The key to financial support for agriculture is to ensure that the investment in financial support for agriculture is increased and the level of scale efficiency is improved [5]. The rural finance and rural economic development in China is born in the rural economic system. A bridge is built between the two through savings rate, savings-to-investment conversion ratio and investment efficiency (Zhi-Guo Ding 2012) [6]. 3) The Rural financial efficiency in the eastern region is better than that in the central and western regions. In recent years, under the guidance of policies to support the western region, the western region of China has been trying to catch up. However, the ability of mobilizing savings in central region is not only far behind by the eastern region, but it may even be left behind by the western region. The central region ranks at the bottom of the indicators of rural financial intermediary allocation efficiency and loan-to-deposit ratio, and there is still a long way to go for rural financial efficiency in China (Cui-Mei Li, Jian-Zhen Cao 2012) [7], The results also obtained Zhao-Juan Meng's data empirical support (Table 2). 4) The main several factors affecting the level of rural financial efficiency: a) Financial environment factors. Jacob Yaron believes that the national macroeconomic environment, industry-biased policies and excessive intervention from government have all reduced the efficiency of rural finance [8]. He-Gui Li thinks that areas with faster economic development are often areas with a good financial ecological environment [9]. Yan-Kai Li believes that the poor domestic financial ecological environment has adversely affected the total amount and efficiency of financial capital allocation and what have to do next is to improve the financial ecological environment [10]. Shen $\mathrm{Gu}$ analyzed and thought that there is an imperfect property right system of rural financial institutions and behindhand backward financial institutions at the present stage in China, the insufficiency of these financial systems is the main reason for the inefficient allocation of financial resources [11]. b) Credit factors. Xi Zhu used the VEC model to analyze the rural credit distribution efficiency. He believed that because of the credit policy under the national forced intervention, the quantity is overvalued but the credit quality is ignored. Under the consumption of financial resources, it has not made a significant contribution to the increase of farmers' income. Therefore, the government needs to build a multilevel and richer rural financial system, lift interest rates, and attract private capital into the market to improve rural financial efficiency [12]. Wei Xue believes that the constraints of rural households' borrowing options and restrictions on the borrowing structure have caused insufficient supply of credit resources, which in turn affected financial efficiency. Rural non-financial institutions have complete information advantages, thereby reducing transaction costs, while formal rural financial institutions have adverse selection and moral hazard. Lower interest rates will also be accompanied by rent-seeking behavior. Therefore, even under the repeated suppression and ban by the government, the rural financial market still has the coexistence of the two [13], The analysis results are shown in the Table 1.c) Organizational system factors. Yi-Ding Yue believes that private finance and formal finance do not conflict. Where there is a lack of formal financial influence, non-financial institutions can play their role, and they are an irreplaceable part of the rural financial system [14]. Zheng Hong analyzed the supervision efficiency of new rural financial institutions and the status of rural financing. The results show that commercial banks lack a comparative advantage in supervision, there is the high supervision efficiency for private capital, and mutual funds can effectively implement supervision, which can significantly improve rural financing situation [15].

TABLE 1. DEA efficiency evaluation results of commercial Banks

\begin{tabular}{|c|c|c|c|}
\hline & $\begin{array}{c}\text { Technical } \\
\text { efficiency }\end{array}$ & $\begin{array}{c}\text { Allocative } \\
\text { efficiency }\end{array}$ & $\begin{array}{c}\text { Cost } \\
\text { efficiency }\end{array}$ \\
\hline $\begin{array}{c}\text { Rural financial } \\
\text { institutions }\end{array}$ & 0.63 & 0.54 & 0.39 \\
\hline $\begin{array}{c}\text { State-owned } \\
\text { commercial Banks }\end{array}$ & 0.85 & 0.76 & 0.72 \\
\hline $\begin{array}{c}\text { joint-stock } \\
\text { commercial Banks }\end{array}$ & 0.91 & 0.85 & 0.89 \\
\hline
\end{tabular}

TABLE 2 The efficiency of converting deposits into loans in rural areas

\begin{tabular}{|c|c|c|c|c|c|c|}
\hline Year & $\begin{array}{c}\text { loan-to- } \\
\text { deposit ratio } \\
\text { in the east }\end{array}$ & $\begin{array}{c}\text { inventory } \\
\text { variation in } \\
\text { the east }\end{array}$ & $\begin{array}{c}\text { loan-to- } \\
\text { deposit ratio } \\
\text { in the centre }\end{array}$ & $\begin{array}{c}\text { inventory } \\
\text { variation in } \\
\text { the centre }\end{array}$ & $\begin{array}{c}\text { loan-to- } \\
\text { deposit ratio } \\
\text { in the west }\end{array}$ & $\begin{array}{c}\text { inventory } \\
\text { variation in } \\
\text { the west }\end{array}$ \\
\hline 2006 & 0.59 & 19000 & 0.54 & 9700 & 0.54 & 8170 \\
\hline 2007 & 0.58 & 23200 & 0.52 & 10900 & 0.57 & 9300 \\
\hline 2008 & 0.58 & 26200 & 0.45 & 15700 & 0.50 & 12500 \\
\hline 2009 & 0.64 & 28400 & 0.49 & 17500 & 0.51 & 15000 \\
\hline 2010 & 0.79 & 19700 & 0.49 & 20700 & 0.56 & 19200 \\
\hline
\end{tabular}


the digital unit of inventory is million and the introduction: The loan-to-deposit ratio and loan gap show the efficiency of fund utilization in rural finance, the loan-to-deposit ratio is equal to the ratio of loans to deposits in rural areas, and it is positively correlated with the efficiency of financial intermediaries. The inventory variation is equal to the difference between deposits and loans in rural areas. The larger the index, the more serious the outflow of rural funds, which is not conducive to the healthy development of rural areas.

\subsection{The Micro Level}

5) The micro level mainly focuses on the research about the rural financial institution operating efficiency. Seibel believes that the profitability of rural financial institutions is poor, and it will be difficult for them to operate continuously by themselves. Hai-Shan $\mathrm{Li}$ and Mei-Jiao Shan believe that informal finance is more efficient than rural formal financial institutions in promoting rural economic growth. Therefore, under the premise of strengthening the supervision of informal financial institutions, it's necessary to guide private capital to play a more important role and improve the efficiency of resource allocation of formal rural financial institutions. In the analysis of rural financial institutions [16], most of the research objects are placed on rural credit cooperatives (Sai-Jun Guo 2011, Xiao-Mei Huang 2012, Wen-Li Wang 2013, Shen Zhong 2014). For example, Jing Li and Shu Chen found that their operational efficiency is generally in a state of medium deviation, based on the data of 311 rural credit cooperatives in the western region [17]. They (Si-Qi Wang, 2017, Ke-Qiang Wang, 2018, Yu Wang, 2019) conducted research on rural banks, and they (JunQi Liu, 2019, Jian-Bin Zhao, 2014, Hu-Feng Yang, Guang-Wen He, 2011) evaluated the efficiency of microlending institutions. Regarding the micro-level financial environment, Xiao-Chuan Zhou put forward constructive opinions on the rural micro-environmental ecological reform in 2004 [18]. Qi-Zhi Deng believes that rural financial products and financial structure are single, financial products and financial instruments are inadequately innovative, with rare species. All of them have led to the problems of rural finance in China, such as payment and settlement efficiency that needs to be improved, unsmooth savings and investment transformation channels, misplaced resource allocation structure, and low level of rural risk management. As a result, it affects rural financial efficiency, farmers' income and pure savings rate, and the neglect of asset quality and operating efficiency (Yaron, 1997) [19], resulting in the low efficiency of rural financial institutions in China, and further acting on resource allocation, which has a negative effect on the development of rural financial markets (Adams 1984) [20].

\section{CONCLUSION}

Among the current methods for evaluating efficiency, the quantitative research of frontier analysis method has become a commonly used method. The relevant software is used to construct the production frontier or cost frontier based on the frontier theory and the theory of minimum cost output maximization. Battese (1995) used the stochastic frontier production function method to conduct an empirical analysis of government-led agricultural credit efficiency. Domestic scholars include Shao-Xin Wu, 2009; In 2011, Hu-Feng Yang and Guangwen He used the same method to analyze the efficiency of the organization. On the whole, the frequency of data envelopment analysis is much smaller. In terms of the use of DEA, there are foreign scholars (such as: Bencivenga, 1991; Battese, 1992; Coeili, 1995; Yang; 1999), domestic scholars (such as: Tao Wen, De-Ping Xiong, 2008; Lin Xiang, Ji-Gang Li, 2010; Yu-Rong Sun, Qi Chen, 2013; Yong-Gang Zhang, Qian Zhang, 2015), who used this method to study the efficiency of rural financial resources. In addition, the current situation of rural financial efficiency in China is analyzed, through the use of panel data regression analysis, or the use of financial indicators to evaluate efficiency and other analytical tools. The above research conclusions provide a theoretical reference for rural financial efficiency and rural economic development in China. Rural Finance Efficiency overall due to the excessive state intervention, ignoring credit quality, seriously hindered the development of private finance, financial constitutions is not perfect, poor efficiency of resource allocation, formal rural financial institutions operating efficiency is low and other causes of China's current rural financial inefficient and underdeveloped balanced, so Combining the meaning of financial efficiency itself, in terms of financial factor input, China should address the problem of insufficient rural financial system and excessive intervention in the rural financial system, improve the rural financial market environment, pay more attention to the strength of private capital, emphasize the role of non-financial institutions, as well as strengthen the innovation of financial tools and products, actively and effectively improve the ability of saving mobilization, the efficiency of the intermediary allocation and so on, in order to make up for the current shortage of effective supply of rural financial capital. Regarding economic output, increase the utilization rate of resources of the conversion rate of savings and investment, and the efficiency of investment. It is affected by unfavorable factors for Chinese agriculture, such as its small scale, dispersion, and susceptibility to natural disasters. Our country can introduce relevant policies to actively guide the development of farmers' industries, thereby generating economies of scale that become larger and stronger.

\section{ACKNOWLEDGMENT}

Time flies. In a twinkling, I have been at Harbin University of Commerce for a year and a half. During my graduate school days in Harbin, I analyzed the relevant aspects of rural financial efficiency followed my teachers. There is not only happiness, but sorrow. There are many gains I have got, as well many futile attempts I have tried. Maybe that is suffering while enjoying as we all know. Here I want to sincerely say thanks to my teachers, classmates and friends who have helped me a lot. 
First of all, it is my tutor Fu-Xiang Liu, I need to thank first. It was she who made me a member of her project group during my re-examination. During this time, she gave me a lot of help both in study and in life. It was also Teacher Liu who made me enter the threshold of economic statistics, so that I had a strong interest in rural finance and spatial econometric economics. Teacher Liu is strict with herself, and she always keeps improving. Besides, She has an enterprising scientific research spirit, as well as a keen and advanced academic insight, which have always encouraged me to continue to advance on the academic road.

At the same time, I would also like to thank many teachers in the teaching and research section of the School of Economics for their help, especially in the choice of study direction and employment, as well as Professor Liu, Professor Zhang, Professor Shen and Professor Ma who taught me and solved my puzzles in class. Finally, I want to thank my family for their continuous help when I am in difficulty. They are my driving force and my strong backing. I love them!

\section{REFERENCES}

1. Qi-Zhi Deng.Realistic review and optimization of rural Financial efficiency from the perspective of function [J].Rural Economy,2010,(5):52-55.

2. Bing-You Cheng. Research on the Efficiency Mechanism of China's rural Financial Market [J]. Rural Economy,2009,(8):65-67.

3. Hong-Dan Zhao. Rural Financial scale, Rural Financial Efficiency and Rural Economic Growth [J]. Economic Survey,2015,(3):28-34.

4. Hong-Mei Wen. Evaluation of rural financial efficiency based on four-stage DEA [J], Journal of Soochow University(Philosophy \& Social Science Edition,2011,(1):107-112.

5. Ji-Gang Li. Analysis of rural financial resource allocation efficiency based on DEA method [J], Finance and Accounting Monthly,2010,(21):40-43.

6. Zhi-Guo Ding. Has rural finance effectively promoted the development of rural economy in China [J], Issues in Agricultural Economy,2012,(9):50-57.

7. Cui-Mei Li, Jian-Zhen Cao. Dynamic analysis and comprehensive evaluation of regional Differences of Financial efficiency in Rural China [J], Journal of Agrotechnical Economics,2012,(3):4-12.

8. Yaron,Jacob,McDonald p. Benjamin, Jr. , and Gerda l. Piprek .Rural Finance ; Issue, Design, and Best Practices. Enviromentally and socially sustainable development studies and monographs series 14[R]. D.C :World Bank,1997.

9. He-Gui Li. Regional ecological environment Difference and economic growth efficiency [J], Finance Forum, 2007,(3):45-52.

10. Yan-Kai Li, Tingchun Han. Research on the mechanism of financial ecological evolution on the growth of real economy $[\mathrm{J}]$, China Industrial Economics, 2011,(2):26-35.

11. Shen Gu, Cheng Li. Defects of financial System: The root cause of Financial inefficiency in Rural China [J], Finance \& Economics,2006,(9):98-102.

12. Xi Zhu, Zi-Nai Li, the efficiency analysis of rural credit in Our country since reform [J], Management World,2006,(7):68-76.

13. Wei Xue, Jia-Zhi Xie. Constraints on farmers' borrowing, Efficiency of Financial Institutions and Evolution of rural Financial system Structure [J], Rural Economy,2010,(11):56-59.

14. Yi-Ding Yue Yu Hu,Bojun Chen. Pareto Optimal State analysis of China's rural financial organizational Structure [J], Systems Engineering,2006,(12):57-59.

15. Zheng Hong. Is the new rural Financial Institution reform feasible? [J], Economic Research Journal,2011,(2):44-58.

16. Hai-Shan Li, Mei-Jiao Shan. Analysis on the informal Financial efficiency and Regional Difference of China's rural economy [J], Seeker,2014,(11):63-67.

17. Jing $\mathrm{Li}$, Shu Chen. Operation Performance and influencing factors of Rural Credit Cooperatives: 311 samples from western China [J], Reform,2012,(8):47-52.

18. Xiao-Chuan Zhou. Improve the legal system, improve the financial ecology [N], Financial News,2004-12-07.

19. Yaron J,B,M P,Piprek G L.Rural Finance: Issues,Design,and Best Practices[J].Vol.14 Washington,DC:World Bank,1997.

20. Adams D W,Graham D H,Von Pischke J D.Undermining Rural Development with Chrap Credit[J]. Westview Press,Boulder CO.1984,1-7 